\title{
Fra Kongeaaen til Ejderen 1695.
}

\section{Af Thade Petersen.}

Omtrent der, hvor man allerede i Fjor begyndte at bygge den Rampe, ad hvilken Færdslen til Rømø i Fremtiden skal klartre op til Kammen af Diget, stod den 8. August 1695 tre Mænd og vidste ikke deres levende Raad til at komme over Aaen med deres Heste og Køretøj.

Det var Danmarks første Søkortdirektør Jens Sørensen, hans Broder Peder, der fulgte ham som hans Skriver, og hans Kusk Jens.

Jens Sørensen er den første, der i større Stil har tegnet et nogenlunde rigtigt Rids af Danmarks Kyster og et brugbart Kort over vore Farvande. Hans betydeligste Forgænger i den Henseende var vel nok Bagge Jensen Wandel, Søn af Pastor Jens Wandel i Magstrup, men det var Jens Sørensens Arbejde, der lagde Grunden til Danmarks Søkortlægning. Han fortjener med Rette det Navn en sen Eftertid har givet ham: "Den danske Hydrografis Far«.

Et af de Krav, som et Søkort naturligt maatte stille var Tilvejebringelsen af et Kort, der viste Landets Omrids. Til Opmaalingen af Kyststrækningerne konstruerede Jens Sørensen selv et Apparat, der viste sig at være ret brugbart, selv om det langtfra ikke maalte med den minutiøse Nøjagtighed, som nuværende Landmaalere stiller til deres Apparater. Han lavede en Vogn, der slog et Slag paa en Klokke for hver 61 Alen den kørte.

Med denne sin »Milevogn« kørte Jens Sørensen i Sommeren 1695 langs med Stranden fra Skagen til Hamborg.

Den 5. August var Jens Sørensen naaet til Kongeaaen. Han stod her ved Vilslev Kirke, der ligger lige ved Kongeaaen. I sin Journal skriver han: "Her ved Vilse Kirke gaar Aaen dicht S. ved Kirken, som adskiller Jylland og Holştein «, og han kunde ikke kommem over Aaen her. Der var ganske vist en smal Fjæl, den bekendte Vilslev Spange over Aaen, Halvdelen af 
Sognet ligger jo Syd for Aaen, men ad denne Spange kunde Jens Sørensen jo ikke komme over med sin Milevogn. Han waatte køre til Gredstedbro 72 Klokkeslag, rigelig $4 \mathrm{klm}$, for at komme over dell. Her ved denne "Græstæ Bro«, som han skriver, noterer han som et Forhold, der interesserer ham ved Siden af sin Landmaaling: "Ved deme Græstæ Bro er en Toldsted, som tages Told af alt det, der over passerer i Købmandskab fra Jylland og ad Holstein, og tages udenrigs Told af Øxen, Hester og andet $\ll$. Her naaede han altsaa ind paa det Omraade, hvor kongeligt og hertugeligt Styre brødes og ogsaa tidt skulde komme til at volde ham Vanskeligheder.

Det første Sted, han syd for Kongeaaen gjorde Holdt, var Ribe, og selvfølgelig maatte han her til Tops i Domkirkens laarn, hvis Højde han maalte til "76 Al. sælandsk, og Brystværket eller Rækkerne oven omkring er af idel Sten og Stenpillerne høje op $2 \mathrm{Al}$. sæl., overalt ovenpaa bedækt med Bly, ingen Spir paa, mens berettes at Spiren der før var paa meget høj faldt ned«. Her oppe fra tog han 16 Pejlinger fra »Esbjerg Klint i $\mathrm{N} \mathrm{V}_{2} \mathrm{~V} \ll$ og $»$ Vilse (Vilslev) Kirke in $\mathrm{N} \mathrm{N} \mathrm{V \ll ,} \mathrm{"S.} \mathrm{Hoved} \mathrm{paa}$ Fanø lige over Aamyndet in $V 5 \mathrm{~N} \ll$, Mandø By in $\mathrm{V} \mathrm{S} V 5 \mathrm{~V}$, itil Vesteds (Vester Vedsted) Kirke in V S V 6 S $\mathrm{S}$ og "Darum liirke in $\mathrm{N} \mathrm{N} \mathrm{V} 4 \mathrm{~V}$ «, altsammen misvisende. Misvisningen maa den Gang have været $8^{\circ}$ mells den nu er 7 Grader. En Efterprøvelse af et større Antal af disse Pejlinger har ganske vist vist, at de ikke er saa nøjagtige, som de kan gøres ned vore Tiler's Instrumenter, men for de flestes Vedkommende er Fejlene kun ret smaa.

Onsdag den 7. August var han naaet ned til Rejsby og tog her ind hos Sognefoged Hans Andersen. Denne synes at have taget gæstfrit imod ham og hans $\mathrm{Hjælpere,} \mathrm{men} \mathrm{stille} \mathrm{Køretøj}$ til hans Raadighed vilde han dog ikke. Han hørte nemlig under Haderslev Hus, altsaa Hertugdommet, og saa kunde det ikke nytte, at Jens Sørensen havde en kongelig Ordre i Lommen, i Følge hvilken alle Embedsmændene skuide være ham behjælpelige og stille Køretøj til hans Raadighed. Hans Andersen henviste ham derfor til de Riberhus Tjenere, "og som vi der i Byen fandt nogle af dem, fik vi Skyds af dem efter Antmanden hs. Exc. Ordre» skriver Jens Sørensen. 
8. August om Morgenen klatrede Jens Sørensen saa op i Rejsby Kirketaarn og tog Pejlinger til Manø Kirke, Rømø Kirke, de nordligste Huse paa Rømø, Ballum Kirke, Kirkerne i Brons, Hvidding og Vester Vedsted samt Ribe Domkirke. Saa var det Punkt da forsvarligt fastlagt, og i Forhold til de simple Midler, som Jens Sørensen raadede over, kunde det næppe ventes at blive bedre. Kun Nabokirken, Hvidding viser saa stor en Afvigelse fra det rette, at der aabenbart maa foreligge en Fejlskrivning, vistnok $\mathrm{N} V$ t $\mathrm{V} 3 \mathrm{~N}$, mens det skulde have været $\mathrm{N}$ V t N $3 \mathrm{~N}$.

Aaer havde Jens Sørensen mødt saa mange af paa sin Tej fra Skagen. Den største af dem, Skernaa, havde han maattet sejle Hest og Milevogn over. De fleste havde han vel kumnet køre over, om ikke andet saa ad den Revle, der gerne har dannet sig uden om Udløbet. Sidst var han kommen over Brons Aa, uden at han saa meget som nævner hvordan. Men Brede Aa var ikke saadan at komme over. Han kalder den Mist Husum Aa. Det var ikke saa underligt, da »Mist Husum Bondebrs (i) Gaarder" var den eneste Bebyggelse i Nærheden af Aaens Udløb.

Fra Aaens Udløb er han "kørt skraas langs op ud med Aaen til Mist Husum Bys sidste Hus i S. t. V. $55 \mathrm{Kl}$. Sl.« De 55 Klokkeslag $=2074 \mathrm{~m}$. Nu er der jo kun en død Gren af Aaen, der gaar i Retning Syd til Vest hen til den sydligste Pold af Misthusum. Den er imidlertid ikke bare $2074 \mathrm{~m}$ lang men omtrent $2700 \mathrm{~m}$, altsaa næsten $500 \mathrm{~m}$ længere end i 1695 .

At Aaen ved sit Udløb under Pres af Flodstrømmen fra syclvestlig Retning mødte en Hindring, har man længe vidst. Det er den, der er Skyld i dens ualmindelig snørklede Lob genmen Engene, og det er især den, der i Hundreder af Aar har tvunget den til at løbe i nordlig ja endog i nord til ostlig Retning, inden den kunde naa ud til Havet.") Her kommer Jens Sorensen nu og siger os, hvor Udløbet var i 1695 og dermed ogsaa hvor langt det er bleven presset Nordpaa siden da. De $526 \mathrm{~m}$, der nu er fra Bohovedet, (omtrent der, hvor Vejen til Ballum Sluise gaar over det gamle Aaløb) til "Gammel Værre«, den

") Se Geografisk Tidsskrift 1926 S. 223-25. 
șrdligste af Misthusum Polde, er Udløbet flyttet fra 1695 til 1919, da det gamle Udløb blev lukket.

Hvordan Jens Sørensen kom over denne Aa, vil vi lade ham selv fortælle om:

"Denne Mist Hu sum Aa gik dyb ud ad Stranden med Blaaler, at vi kunde ikke køre uden om den. Aaen i sig selv var med Udfalds Vand en smal dyb Strøm og Blaaler paa begge Sider, at man kunde ikke komme nær Vandet. Her var ingen Bro, som berettes, paa nogle Mile nær op ad Landet over Aaen, on ingen Baad saa stor og dygtig, der kunde føre vor Milevogn over. Og ingen By var paa andre Side Aaen nembre end som Ballum By. Thi fandt vi nede Aaen en Mand fra Øerne kommen med sin Baad at hente Torv, fik vi saa 2 Mand af Nist Husum Folk, som hjalp os med samme Tørvebaad over Aaen med Milevognen, og hjalp os paa andre Siden paa Marken at tage to Heste og sætte for Milevognen med al vort $\mathrm{Pa}$ gagie paa, og det med største Hastende., saasom Vandet begyndte at flove og voxe, at vi kunde køre frem langt ude paa Stranden, mens Vandet var ude, fordi vi kunde ikke komme frem paa Landet eller i Landbredden for Strømme og bløde Grofter. Selv gik vi til Fods barfodet, nogle Steder maatte vi spænde fra Heste først at bringe ledige over de bløde Aaer og drage Milevognen ledig over og bære Pagagen over".

Jens Sørensen fik altsaa at vide, at der ikke var nogen Bro over Aaen "paa nogle faa Mile nær op ad Landet«."; Det var nu vist at slaa til med den store Hammer. Der var jo da i lige Linje ilke mere end 3 Kilometer op til Færgegaarden, og der var vel den Gang næppe mange Grøfter, der kunde hindre ham i at køre lige til. I alle Tilfælde maatte der være Vej fra Højbjerg op til Færgegaarden. Ja havde det været en Del Aar før, kunde Mændene fra Midthusum maaske have givet ham Anvisning paa at køre den Vej. Da var der endog en Bro over Aaen omtrent paa det Sted, hvor Færgegaarden ligger, men den var for nogle Aar siden bleven reven bort af en Isstormflod som den i 1.839, og der var nu slet ingen regelmæssig Overfart, vel i det hele ingen, der havde Baad til det. Først tre Aar senere, 1698, fik Grev Hans

*) Johannes Knudsen: Søkortdirektør Jens Knudsen S. 146. . 
Schack i Folge et Dokument, der opbevaredes i Arkivet paa Trojborg, Lov til at indrette en Færge med Bäad og Pram i Stedet for den bortskyllede Bro og tage 4 Skilling for at føre en Vogn over Aaen, 1 Skilling for en Okse eller Ko, 1 Skilling for Parret af Smaafæ (Faar, Svin og Kalve) og ligeledes for en Person. Indtil 1801 havde Folk fra Egnen haft en billigere Takst. Den daværende Færgeejer Mads Bruun satte den imidlertid op i Højde med, hvad andre betalte. Det kom til Retssag om Sporgsmaalet. Udfaldet af denne kender jeg dog ikke.

I 1878 blev den nuværende Bro bygget og derned faldt Færgen bort. Ogsaa Færgekroen har tabt sin fordums Betydning. I gamle Dage, da man skulde med Færgen over Aaen, gav det jo ret naturligt et Ophold i Kroen, vist tit noget liengere end strengt nødvendigt. Nu er Kroen Afholdsbeværtning, og Bilerne suser forbi den.

Kunde Jens Sørensen saaledes ikke komme over Aaen ved Færgegaarden, saa var der ganske vist "nogle Mile» til det nærmeste Overfartssted nemlig Bredebro eller Brewadt som det tidligere hed. Der kunde Isfloden ganske vist ogsaa nok vare naaet op til, men dog næppe med saadan Styrke, at den rev Broen om. Den vides da heller ikke at have gjort det. I lige Linje blev der vel næppe mere end et Par Mil, men i lige Linje gik der heller ingen Vej. Der kunde derfor godt siges at være nogle Mil derop, og det var et Held for Jens Sørensen, at Manden fra Rømø kunde sætte ham over Aaen ved Misthusum.

Manden, der førte ham over Aaen, traf han for Resten senere paa Rømø. Han hed Petter Tagholm og boede i Tagholm.

Det blev Aften, inden Jens Sørensen fik tilbagelagt de fire Kilometer langs det uvejsomme Havbryn og naaede til Ballum, hvor han »losseret ind hos sl. Herredsfogdens Enke Dorthea sl. Jens Aagesens, som var et meget prægtigt Lossement, og bleve vi af samme Enke meget høflig og vel begegnet. Hans Majestæt haver selv losseret udi samme Hus tilforn."

Det er ikke umuligt, at den Majestæt, Fru Dorthea med Stolthed har omtalt som Gæst paa sin Gaard, kan have været. Christian IV., der vitterlig var i Byen den 7. September 16ł?. I min Artikel her i Aarbøgerne 1935 om »Kristian IV og Hav- 
lien ved Ballum« antog jeg det for givet. Der har imidlertid senere været Kongebesøg i Ballum.

Den 8. Oktober 1689 rejste Christian $\mathrm{V}$ efter en Revu i Ribe over 7000 Mand, der skulde sendes til Skotland, om Aftenen til Ballum. Det er da ikke usandsynligt, at det er ham, der har boet der. Det har i saa Tilfælde sikkert nok været, mens Fru Dorthea selv var Kone i Huset. Hun var altasa ikke uvant med fornemt Besøg.

Den næste Dag, den 9. Oktober. kører han med Skyds fra Ballum. der var kongerigsk Enklave, til Hjerpsted og øjensynlig videre til Højer. Naar han nemlig i Hjerpsted bemærker: "alt er fwrsteligt" ligger der deri sikkert et Suk over, at han ingen Befordring kunde faa paa det Sted. Men det blev værre endnu. I Højer tog han ind "udi Hamborger Herberg hos Værten Hendrik Simonsen ved Torvet«. Ogsaa her mødte han Vrangvilje med Hensyn til at skaffe sig Skyds. han finder det endog nødvendigt at lade sit kongelige Rejsepas oversætte til 'Tysk og sende en tysk Ansøgning til Amtmanden i Tønder wom at faa nyde fri Skyds paa det fyrstelige«, saadan som han havde det paa kongeligt Omraade. Den fik han imidlertid straks tilbage. Ansøgningen skulde sendes til "hans fyrstelige Durclilauchtighed". Det vilde naturligvis i bedste Fald give stor Tidsspilde. Imidlertid kører han til Møgeltønder og klager sin Nød for Greven - her var han jo igen paa kongerigsk Grund. Greven gaiv ham da fire Heste og en Vogn til at køre han tre Mil.

Han mødte imidlertid her ogsaa noget andet end hertugelig Vrangvilje eller Smaalighed, hvad det nu har været. Her støder han forste Gang paa det, at Mennesker har taget Kampen op nod Havet, idet de ved at bygge Diger har sat Grænser for dets Eneherredømme. Især er han optaget af de Sluser, der byg. gedes for at give Indvandet Afløb.

Man var netop ved at bygge en Sluse vel Rudbol. Der gjorde han sig gode Venner med Lederen af Arbejdet, Johan Andris, som "tog os med sig, og med en Baad fore vi ind udi alle Slysserne at bese dem, de var meget kostbar bygte, med 3 Tomme Ege-Planker under og over og paa alle Sider beklædte, 
meget tæt sammenfuget, med Bøge Bundstokker, grønne og meget stærke, 1 Kvarter nær hverandre, Opstandere af fint Fgetræ, stod en paa hver Ende paa Bundstokkene, og Overtræ af Egetømmer oven paa hver to Opstandere; dette Tømmer var mest 3 Kvarter tykt i hver Kant og 4-kantigt. Diget var højt efter Vaterpasset 11 Alen; oven paa, som Vejen gik langs ad bredt 6 Alen; under i Grunden bredt med Jord tilfyldt, paa hegge Sider skraas op tilfyldt, var vel 30 Alen. Disse Slysser synes at være et stort kostbart Værk, og berettes at hver Sly'sse koster over 15,000 Rd. Udi hver Slysse hænger \& Halvporter, som Vandet, naar Floden kommer, selv slaar til, meget tæt fugede, og naar Ebben gaar ud igen, at Vandet udentils falder fra, saa trænger Vandet, som indentils er og af Landet haver derigennem sit Udløb, Portene selv op igen og flyder ud. Portene staar paa meget store Kobbertappe udi Kobberpander, og oventils med store Jerntapper«.

Da den ny Christian Albrechtskog endnu ikke var inddiget, har han maattet om over Deedsbøl. Her vendte Kudsken fra Schackenborg om. Jens Sørensen maatte saa leje en til at høre til Opholm for to Daler. Ogsaa senere havde han nu cg da Besvær med "fyrstelig" Vrangvillighed, saaledes isar $i$ Husum, hvor han den 16. August skriver:

"Som hs. fyrrstl. Højhed") selv var der til Stede og havde ladet sig hyllige i Gaar, som var den 15. Augusti, gik vi op paa Slottet, der mangfoldige af Landets Indbyggere og Sollicitanter vare forsamlede inde paa en stor Sal, som $\mathrm{Hr}$. Secretrerer og Geheimeraad Wedderkopp**) stod ved et Bord og tog imod alle Supliker og igennemlæste dem og gav straks derpaa ResoJutioner; leverede vi og hannem vor Supplik, som $\mathrm{Hr}$. Amtman(len i Tonderen havde paaskreven og remitteret til hs. fyrstl. Durchlauchtighed selv, med hosfølgende Kopi af hs. kongl. Majtts. allern. med givnee fri Rejsepas paa Tysk udsæt. Naar han samme Breve havde læst, leverede han os dem igen og sagde: Naar his Maj. skrev Fyrsten til og begærede noget, saa fik han det. Som vi formærkte, vi havde ingen Befordring af

*) Hertug Frederik IV. mark.

**) Holsten-Gottorpsk Minister (1637-1721), ivrig Fjende af Ihan- 
dem at forvente, gik vi saa ud om Husum Stads østre Port, og maalte Gaden fra det rderste Hus indad«.

Den 18. August var Jens Sørensen imidlertid naaet til Tomming. Han havde nogen Vanskelighed ved at komme over Ejderen, men hans videre Rejse til Hamborg interesserer os ikke i denne Sammenhæng. Det har Udgiveren af hans Optegnelser ogsaa fundet.

Den 21. September er Jens Sørensen igen i Husum for paa Tilbagerejsen at besøge Vesterhavsøerne og beskrive dem og deres Farvande. Mærkeligt nok har han fuldstændig ignoreret Nordstrand og Pelworm, tillige med de Smaahalliger omkring ved dem og er sejlet lige til Før, hvor han landede ved $\gg$ Dorpet Wik, som er fyrstelig«. Baaden havde taget Grund omtrent 50 Favne fra Landet. Men der kom straks en Vogn "kørendes ud til os som kørte vos og vort Tøj i Land«. Vyk har aabenhar overrasket ham. Den wser ud $\mathrm{i}$ alting som en liden Købstad med Købmænd, Kræmmere og alle Slags Haandværkere udi og Rebslagere«.

Før har da aabenbart, som naturligt er, været stærkt præget af sine Indbyggeres Søfart. Vi behøver da ogsaa kun șr Aar længere frem for at finde den forste Meddelelse om, at Øens Søfolk ikke alene var med i Grønlandsfarten, men selv utrustede og bemandede Skibe til den,") og omtrent en Mellneskealder før vides de at have ført Grønlandsfangere fra Hamborg. **) Jens Sørensen kunde da heller ikke undgaa at lægge Mærke til, at der laa mange Smakker og Bøjerter, en Del med lavt Vand paa tørre Sanden, en Del flot

Efter at Jens Sørensen et Par Dage havde maalt og pejlet Øen paa alle Kanter og derefter et Par Dage var bleven opholdt ai Storm, sejlede han Søndag den 29. Sept. "saasnart Prædiken var ude" til Amrum, som han maalte og pejlede paa langs og tværs. Derfra sejlede han til List, som han baade pejlede og maalte meget omhyggeligt uden at foretage sig noget paa selve Sild.

At han gjorde denne Forskel paa List og det øvrige af Øen laa maaske til Dels $i$ at List "hørte Kongen til« mens paa Sild

*) Provinsialberichte 1827. S. 661.

*) Wanda Desau: Schlesw.-Holst. Grönlandsfahrt S. 217. 
var »alt fyrsteligt" men Hovedsagen var vel nok, at han paa hele sin Rejse fra Skagens Gren til Altona ikke havde fundet Mage til Indsejling fra det aabne Vesterhav til den sikreste Ankerplads paa dybt Vand bag Klitterne paa List. Christian IV lıavde godt nok haft Øje for Listerdybs strategiske Betydning*) og Skibe søgte tit Læ bag List." ${ }^{*}$ Fejlen ved det var imidlertid, at der var for langt og for daarligt Farvand ind til lastlandet og dets Havnepladser. Der var jo den Gang ikke nogen Hindenburgdæmning og ikke Udsigt til en Dæmning fra det Udløb af Bredeaa, der voldte Jens Sørensen saa stor Vanskelighed, til Odden paa Rømø.

Den 4. Oktober »om Morgenen imod Dagningen« gik han "til Sejls« ad Rømø til og kom til Havneby »om Middags Tid«. F'aa Rømø opholdt han sig i 4 Dage og tog Pejlinger til mange forskelige Punkter samt udførte med sin Milevogn en Rakke Maalinger, der bidrager til at give rigtig Forstaaelse af mange Ting paa Øen for lige ved halvtredje Hundrede Aar siden, men "det er en anden Historie ", som jeg tænker at gøre nærmere Hede for i min "Rømøs Historie», der forhaabentlig snart kan udkomme.

. Tha de Petersen.

*) Se Sønderj. Aarbøger 1935 S. 263-i3.

*) Jacobsen: Skibsfarten i det danske Vạdehav S. $18 \pi$. 